\title{
CONCEPÇÕES DE INTER-RELAÇÕES CIÊNCIA-TECNOLOGIA- SOCIEDADE NA TEMÁTICA MATRIZ ENERGÉTICA: UM ESTUDO COM LICENCIANDOS EM FÍSICA
}

\author{
Tiago Clarimundo Ramos ${ }^{1}$ \\ Marcos Fernandes Sobrinho ${ }^{2}$ \\ Wildson Luiz Pereira dos Santos ${ }^{3}$
}

\begin{abstract}
RESUMO Este estudo, de cunho qualitativo interpretativo (MOREIRA, 2011), apresenta e discute uma alternativa teórico-metodológica de análise de concepções de inter-relações Ciência-Tecnologia-Sociedade (CTS) na temática matriz energética, em enunciações de estudantes do segundo período do curso de licenciatura em Física de uma universidade pública do sudoeste goiano. A parte empírica da pesquisa contemplou a aplicação de questionário, discussão em aula e produção de texto por parte dos sujeitos participantes. Os dados foram construídos, no segundo semestre de 2014, no campo de uma investigação mais ampla sobre práticas pedagógicas de educação CTS na formação de professores, inserida no grupo de pesquisa Educação Científica e Cidadania da Universidade de Brasília. Identificamos que embora haja certo fatalismo quanto às apostas futuras da matriz energética nacional pautada, principalmente, no petróleo e na geração hidrelétrica, há aspirações pela transição para outras fontes renováveis (como solar e eólica). Em nenhum momento constatamos algum tipo de correlação, por parte dos estudantes, entre problemática energética e atual modelo de produção e consumo de bens materiais, alimentado por determinada matriz, que se ancora na obsolescência programada e no consumismo desenfreado. Em nosso entendimento, é bastante pertinente repensar a matriz energética, no sentido de buscar fontes que sejam mais "limpas" e renováveis. Contudo, só isso não basta, pois não haveria, dentro do modelo socioeconômico vigente, recursos suficientes para atender à crescente demanda de energia degradada. Diante disso, sentimos a necessidade de mais investimentos na exploração dessa temática na formação de professores, não apenas pela carência de conhecimentos sobre diferentes fontes e seus impactos (positivos e negativos), mas principalmente para se avançar em processos formativos que viabilizem desenvolver concepções mais críticas das interrelações CTS, no sentido de reconhecer como tudo isso se articula à busca por outro modelo de desenvolvimento que se serve de uma nova matriz e ponha em xeque o mito de "progresso infinito".
\end{abstract}

Palavras-chave: Ensino de Matriz Energética. Educação CTS. Formação de Professores.

\section{CONCEPTIONS OF SCIENCE-TECHNOLOGY-SOCIETY INTERRELATIONS IN THE ENERGY RESOURCES THEMATIC: A STUDY WITH PHYSICS LICENCIATES}

\footnotetext{
${ }^{1}$ Professor do Instituto Federal Goiano - Câmpus Rio Verde. Email: tiagoclarimundo@ig.com.br;

${ }^{2}$ Professor do Instituto Federal Goiano - Câmpus Urutaí. Email: marcos.sbf@gmail.com;

${ }^{3}$ Professor do Programa de Pós-graduação em Ensino de Ciências do Instituto de Química e do Programa de Pós-graduação em Educação da Faculdade de Educação da Universidade de Brasília. Email: wildson @unb.br
} 
ABSTRACT This qualitative and interpretative study (MOREIRA, 2011) presents and discusses a theoretical and methodological alternative of analyzing the conceptions of Science-Technology-Society (STS) interrelations in the energy resources thematic. The study based on enunciations by first-year students majoring in Physics in a public university located in the southwest of Goiás. The empirical part of the research contemplated the use of questionnaires, class discussions and text production by the subject participants. The data was collected in the field of a broader investigation about pedagogical practices in STS education in the formation of teachers. The investigation was inserted in the research group named Scientific Education and Citizenship in Brasília University. The study identified that, although there is a certain fatalism related to future challenges of the national energy resources based mainly on petroleum and hydroelectricity, there are aspirations for the transition to other renewable sources (e.g. solar and wind-sourced type). In no moment, there was a confirmation by the students, of some sort of correlation between energy problems and the current production system and consumption of material goods, supplied by a certain resource, which anchors to the programed obsolescence and unrestrained consumerism. Considering the circumstances, rethinking the energy resources is very pertinent, in the sense of seeking for cleaner and renewable sources. Nevertheless, that is not enough, for there would not be, in the current socioeconomic model, sufficient resources to supply the increasing demand of degraded energy. Thus, there is a need of more investments on the investigation of this theme in the formation of teachers, not only for the lack of knowledge about different sources and their impact (positive and negative), but mainly to advance in formative processes which enable the development of more critical conceptions of the STS interrelations. Such conceptions would recognize how all of the circumstances lead to the search for another development model, which must be supplied by new resources and put the myth of "infinite progress" into question.

Key-words: Energy Resources Teaching. STS Education. Formation of Teachers.

\section{INTRODUÇÃO}

A matriz energética de um determinado país, estado ou em qualquer contexto local é um instrumento que, em suas perspectivas de evolução, busca representar de forma ampla as diversas relações entre fontes energéticas com sua cadeia de produção e consumo, sendo essencial ao planejamento e estabelecimento de estratégias mais adequadas para cenários futuros (REIS; FADIGAS; CARVALHO, 2012). Contudo, no caso do governo brasileiro, pouco se tem dedicado à elaboração de uma matriz energética nacional com projeções futuras de cenários evolutivos e incertezas (BRONZATTI; IAROZINSKI NETO, 2008). O que mais se observa, já há longo tempo, é o balanço energético nacional apresentado anualmente pelo Ministério de Minas e Energia (MME) que tem permitido uma análise do ocorrido nos últimos anos. 


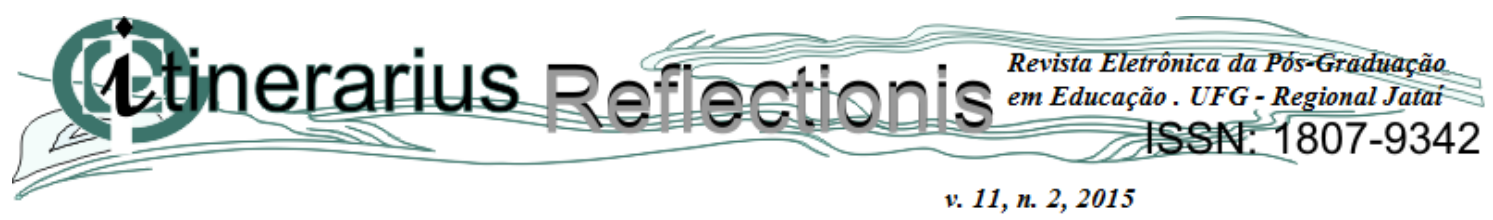

Ademais, não há dúvidas de que a maior ou menor participação de diferentes fontes de energia em determinada matriz é função de uma combinação de variados fatores, como disponibilidades de recursos, preços e leis ambientais. Eis uma questão que se articula a políticas de Estado e a preocupações relacionadas ao crescimento do Produto Interno Bruto (PIB). Tudo isso, porém, parece funcionar sob duplo signo de dependência e de dominação. Enquanto de um lado, há uma dependência em relação à oferta de energia para atender às demandas da sociedade; de outro, tem-se a dominação sob o aspecto financeiro, comercial e tecnológico das grandes corporações que forçam a caracterização do consumo a seus próprios interesses (PAIVA, 2012).

\footnotetext{
“[...] as mudanças climáticas, o aquecimento global, o esgotamento dos solos e degradação da água, a destruição das florestas e ambientes selvagens, o esgotamento dos recursos naturais, a extinção acelerada de espécies vegetais e animais, a poluição do ar, terra e mar, o acúmulo de rejeitos e substâncias tóxicas de difícil armazenamento que colocam em risco as gerações do presente e do futuro, o degelo das calotas polares, o aumento da incidência de furacões, tornados e tempestades de grande intensidade, as secas prolongadas e inundações sem controle são todas características do momento histórico que estamos vivendo que se tornam cada vez mais evidentes, colocando em xeque o modelo econômico, social e político, hegemônico no mundo e responsável por tais acontecimentos." (ZEN, 2007, p. 111).
}

Essas são algumas razões que justificam a importância de explorar a problemática energética no ensino, visando à formação de cidadãos capacitados para intervir na sociedade; que, conforme salienta Bermann (2003), encontra-se carente de espaços institucionalizados onde as pessoas possam ter oportunidade de debater essa questão, contrapondo-se à busca do "ótimo".

Com base nessas considerações, objetivamos com o presente estudo, de cunho qualitativo interpretativo (MOREIRA, 2011), identificar e analisar concepções de interrelações CTS na temática matriz energética, de um grupo de estudantes do segundo período de um curso de licenciatura em Física, em uma universidade pública do sudoeste goiano, a partir de enunciações motivadas pela realização de uma prática pedagógica pertinente à temática, que estimula a construção de argumentos por parte dos graduandos.

\section{EDUCAÇÃO CTS, O ENSINO DE MATRIZ ENERGÉTICA E ARGUMENTAÇÃO}


De acordo com Chrispino, Lima, Albuquerque, Freitas e Silva (2013), o movimento CTS teve sua origem, em meados do século XX, como uma crítica ao modelo linear de progresso apregoado, sobretudo nos Estados Unidos e na Europa, de que os avanços científicos e tecnológicos se traduziriam inexoravelmente em desenvolvimento econômico e bem-estar social. Diante disso, ao longo dos anos 1970-1980, novos valores e ideais CTS passaram a ser incorporados aos currículos e materiais didáticos, sobretudo em países do Hemisfério Norte. No cenário brasileiro, por sua vez, a denominação CTS só começou a aparecer nas pesquisas e materiais de ensino, no final da década de 1990; embora já existissem, mesmo antes disso, materiais que contemplavam um enfoque social de Ciências. Contudo, na última década, têm se constatado um volume significativo de trabalhos acadêmicos brasileiros em CTS, no Ensino de Ciências (ver, por exemplo, CHRISPINO et al. 2013; ABREU; FERNANDES; MARTINS, 2013), além de uma série de recomendações que se aproximam de uma perspectiva CTS nos documentos educacionais legais (SANTOS, 2012).

No contexto de uma educação CTS é inaceitável admitir a existência de uma ciência absoluta e neutra. Conforme sugere Fourez (1995), esta só é possível quando se dispõe a esconder particularidades de nossa sociedade, de nossa visão e da nossa situação; porém, essa postura conduz a uma sociedade tecnocrática onde se busca legitimar decisões sociopolíticas, unicamente pela lógica científica. De igual modo, é preciso expandir ainda as concepções de tecnologia, pois reconhecê-la simplesmente como ciência aplicada implica uma visão bastante estreita (DUSEK, 2009). Segundo Fourez (2003), a construção de uma tecnologia na maioria das vezes requer outras considerações (sociais, econômicas, culturais etc.) que vão muito além de uma aplicação científica. Pinto (2005) acrescenta que a compreensão de tecnologia pode ser significativamente ampliada quando se funda, sobretudo, na noção da própria historicidade do ser humano e do trabalho.

No entendimento de Dagnino (2010a), a história da tecnologia e da própria produção de conhecimento tem sido fortemente marcada por uma trajetória de intensificação da produtividade, economia e alienação do trabalho humano, maximização do lucro e degradação ambiental. E, a pesquisa em Ciência e Tecnologia (C\&T) tem gerado uma tecnologia (convencional) que não atende a inclusão social, mas a interesses materialistas (LACEY, 1999 apud DAGNINO, 2010a) e capitalistas (FEENBERG, 2002 apud DAGNINO, 2010a) de determinados atores que detém poder econômico, político, etc. Por isso, defende-se que melhor seria investir em tecnologias sociais, que fossem construídas com outras 


\section{(ttinerarius Reflectionis 20 20

intenções: (I) de viabilizar a sustentabilidade econômica, social, ambiental, política e cultural de empreendimentos solidários; (II) de engendrar formas alternativas de produção e organização social àquelas instauradas pelo capital; e, (III) em um nível mais avançado, de ocupar o lugar da tecnociência, primando pela construção de uma nova economia. (DAGNINO, 2010b).

Para tanto, de acordo com Japiassu (2005), a sociedade precisa ser repensada, de tal forma que a identifique, mormente, pela capacidade das pessoas de questionarem as próprias representações coletivas estabelecidas, jamais se tornando justificador de um status quo. Nessa perspectiva, portanto, entendemos que um ensino de matriz energética na educação CTS deve ir muito além de um estudo de conteúdos científicos; um de seus propósitos mais nobres visa à formação do cidadão (SANTOS; SCHNETZLER, 2010), que seja capaz de perceber, inclusive as contradições e inconsistências presentes em questões sociocientíficas, relacionadas a padrões de desenvolvimento científico e tecnológico.

Somado a esse interesse, na parte empírica desta pesquisa, a partir de discussões mediadas pelo pesquisador-formador, buscamos estimular os licenciandos a construírem argumentos que, de alguma forma, servissem para sustentar seus pontos de vista sobre questões relacionadas à matriz energética. Contudo, julgamos que a enunciação de uma conclusão seja acompanhada, sobretudo, de dados e justificativas que permitam ampliar a compreensão dos problemas.

Entendemos que promover a argumentação em sala de aula possibilita, entre outros, maior exposição por parte dos estudantes (seja verbalmente ou por informes escritos), levando-os a migrar da condição de receptores para construtores de conhecimento. Destarte, a fim de que pudéssemos nos dedicar a compreender como estes argumentos são construídos e que compromissos (explícitos ou implícitos) se manifestam nas enunciações desses sujeitos, concebemos para este estudo um quadro de análise pautado nas seguintes categorias: (I) componentes do modelo de argumentação de Toulmin ${ }^{4}$ (dado D, conclusão C, garantia G, apoio A, qualificador Q e refutação R) (TOULMIN, 2006); (II) natureza dos argumentos (científica, tecnológica, social, cultual, econômica, ambiental e política) (PATRONIS; POTARI; SPILIOTOPOULOU, 2007); e, (III) inter-relações CTS (influências da C na T;

\footnotetext{
${ }^{4}$ No modelo de argumentação de Toulmin (2006), são apresentados alguns elementos básicos relativos à estrutura justificatória do argumento, de modo a demonstrar ao menos uma garantia $(\mathrm{G})$ de que tomando certos dados (D) é legítimo passar à conclusão (C). Todavia, podem existir ainda outros três elementos para complementar sua apresentação: qualificador modal (Q) que, via de regra, se manifesta como advérbio (como certamente, improvavelmente, etc.) para indicar a força da garantia; apoio (A) que visa dar sustentação à garantia; e, refutação (R) que indica as circunstâncias de exceção, nas quais se contesta a garantia.
} 
influências da T na C; influências da $\mathrm{C}$ e/ou T na $\mathrm{S}$; influências da $\mathrm{S}$ na $\mathrm{C}$ e/ou T; natureza da C; natureza da T).

\section{INSTRUMENTOS E PROCEDIMENTOS INVESTIGATIVOS}

Neste trabalho, apresentamos e discutimos uma alternativa teórica-metodológica de análise de concepções de inter-relações CTS na temática matriz energética, em enunciações de estudantes de um curso de licenciatura em Física. Os dados foram construídos, no segundo semestre de 2014, no campo de uma investigação mais ampla, do primeiro autor, na formação inicial de professores, que investiga contribuições e entraves de práticas pedagógicas de educação CTS na temática matriz energética, inserida no grupo de pesquisa Educação Científica e Cidadania (GPECC) da Universidade de Brasília. Embora apenas o primeiro autor tenha desempenhado os papéis de pesquisador e formador, outros dois pesquisadores do GPECC também contribuíram com as análises.

Segundo Moreira (2011), o problema da validade e da confiabilidade em pesquisa qualitativa aponta para cuidados, do ponto de vista metodológico, considerados imprescindíveis e capazes de possibilitarem o atingimento de resultados e/ou conclusões confiáveis. Assim, para minimizar a influência por parte das concepções dos pesquisadores, consideramos oportuno enfatizar nossa vigilância com o compromisso ético de rigor e cuidados metodológicos, mormente, consoante ao duplo papel assumido por parte do pesquisador-formador; vez que nosso interesse central se pautou em processos formativos a partir de interações dos licenciandos com a temática de pesquisa.

Em síntese, conforme exposto nas alíneas a seguir, o presente estudo contemplou a construção de dados empíricos por meio de questionário e produção de texto dissertativoargumentativo; mais um processo de análise com indicadores e sinalizações relevantes ao ensino de matriz energética na educação CTS.

\section{a) Questionário}

A primeira de quatro questões aplicadas aos licenciandos trata de conhecimentos relacionados às principais fontes de energia utilizadas na matriz energética e na geração de energia elétrica brasileira e mundial. Na segunda, fizemos questionamentos sobre projeções futuras para cada fonte da matriz energética nacional. Na terceira, apresentamos itens 


\section{tinerarius $\mathrm{nof}$

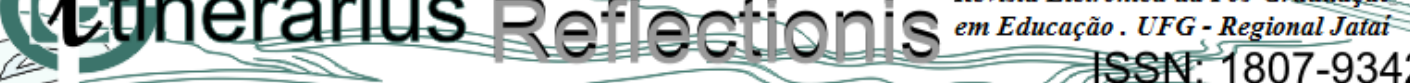 v. 11, n. 2,2015}

relacionados aos impactos da produção e consumo energético. Por fim, na quarta questão, expusemos alguns itens relacionados à participação social em tomadas de decisão, modelo linear de progresso e atividade científica-tecnológica, inspirados no Views on ScienceTechnology-Society ${ }^{5}$ (VOSTS) (AIKENHEAD; RYAN; FLEMING, 1989).

b) Produção de texto dissertativo-argumentativo

Antes da aplicação deste instrumento, a parte empírica desta pesquisa contou com uma aula sobre hidrelétricas ministrada aos licenciandos, na qual foram abordados conhecimentos científicos, tecnológicos e potenciais repercussões (positivas e negativas) associadas a tais empreendimentos. Ao final dessas discussões, requeremos de cada estudante a produção de um texto dissertativo-argumentativo, para que se manifestasse sobre a seguinte questão:

- No Brasil, a geração de energia elétrica, predominantemente centrada nas usinas hidrelétricas, precisa ou não ser repensada?

Assim, neste percurso metodológico, nos preocupamos em instaurar primeiro uma exploração mais geral do tema, visando alcançar maior comprometimento dos sujeitos participantes com posterior processo de construção de argumentos em suas tomadas de decisão.

\section{c) Processo de análise}

Tendo em vista aos propósitos desta investigação e à luz dos referenciais balizadores apresentados na seção Educação CTS, o ensino de matriz energética $e$ argumentação, este processo consistiu em analisar todo material empírico gerado por meio das respostas ao questionário e textos produzidos pelos estudantes.

\section{RESULTADOS DO QUESTIONÁRIO}

A turma envolvida na pesquisa totalizava 11 licenciandos, dos quais dez estavam presentes no dia da aplicação do questionário. Com base nos resultados obtidos para a primeira questão, constatou-se que apenas um (1/10) dos licenciandos sabia que o petróleo figurava como principal fonte na matriz energética brasileira; e, apenas dois $(2 / 10)$ admitiram

\footnotetext{
5 O questionário VOSTS foi originalmente elaborado por um grupo de pesquisadores canadenses, da Universidade de Saskatchewan, com o objetivo de avaliar concepções de inter-relações Ciência-TecnologiaSociedade (AIKENHEAD; RYAN; FLEMING, 1989).
} 


\section{(titnerarius Reflection is 2

o protagonismo do carvão mineral na matriz elétrica mundial. Apesar disso, oito (8/10) reconheceram que o petróleo era a fonte mais utilizada na matriz energética mundial. No tocante à geração de energia elétrica no Brasil, todos reconheceram que a fonte mais recorrente era a hidráulica.

Na segunda questão, ao serem indagados sobre qual(is) fonte(s) de energia eles suspeitavam que seria(m) utilizada(s) mais intensamente, na matriz energética brasileira, nas próximas décadas, as maiores apostas foram para petróleo, hidráulica e gás natural (vide tabela). De outro lado, a expectativa para o uso de energia nuclear foi baixa. Constatamos ainda certo equilíbrio, em termos de concordância e discordância, tanto para outras fontes renováveis como para carvão mineral.

Tabela: Resultados para a segunda questão - Para as próximas décadas, qual(is) fonte(s) de energia você suspeita que será(ão) utilizada(s) mais intensamente, na matriz energética brasileira?

\begin{tabular}{|c|c|c|c|c|c|c|}
\hline Resposta & Petróleo & $\begin{array}{l}\text { Carvão } \\
\text { mineral }\end{array}$ & $\begin{array}{c}\text { Gás } \\
\text { natural }\end{array}$ & Nuclear & Hidráulica & $\begin{array}{l}\text { Outras fontes } \\
\text { renováveis }\end{array}$ \\
\hline Discordo plenamente & 1 & 2 & 1 & 3 & 1 & 0 \\
\hline $\begin{array}{l}\text { Discordo em grande } \\
\text { parte }\end{array}$ & 0 & 1 & 0 & 4 & 0 & 4 \\
\hline Não sei responder & 1 & 3 & 3 & 1 & 1 & 2 \\
\hline $\begin{array}{l}\text { Concordo em grande } \\
\text { parte }\end{array}$ & 5 & 3 & 5 & 0 & 3 & 3 \\
\hline Concordo plenamente & 3 & 1 & 1 & 2 & 5 & 1 \\
\hline
\end{tabular}

Fonte: Elaboração própria.

$\mathrm{Na}$ terceira questão, apenas quatro (4/10) licenciandos concordaram plenamente que chuva ácida tinha alguma relação com os processos de produção e consumo de energia. Boa parte da turma não soube responder (4/10) ou discordou plenamente (2/10) dessa relação, demonstrando falta de conhecimento a respeito do que, de fato, era chuva ácida. Além disso, sete (7/10) concordaram (em grande parte ou plenamente) que tais processos tinham relação com a mudança climática global, reconhecendo, de certa forma, a influência de ações antropogênicas nesse fenômeno; dois (2/10) discordaram em grande parte; e, um único (1/10) não soube responder.

Outrossim, com base na análise das respostas à última questão, identificamos que ninguém contestou a afirmação de que os pesquisadores que atuam no campo da energia são as pessoas mais indicadas para tomarem decisões a respeito da matriz energética. Apenas três (3/10) tenderam a discordar (em grande parte) do modelo linear de progresso, no qual pesquisadores produzem novos conhecimentos científicos que geram novas tecnologias que, por sua vez, vão resolver os problemas da sociedade. De igual modo, somente dois (2/10) manifestaram discordância (em grande parte) à afirmação de que os pesquisadores se 
preocupam com todos os efeitos de suas descobertas, porque buscam alcançar um mundo melhor para se viver. Desse modo, podemos afirmar que os licenciandos participantes da pesquisa demostraram, em grande parte, não apenas carência de conhecimentos sobre a matriz energética, mas concepções pouco críticas das inter-relações CTS.

\section{RESULTADOS DA PRODUÇÃO DE TEXTO}

A análise dos textos evidenciou que a prática pedagógica instaurada nesta pesquisa favoreceu a construção de argumentos por parte dos licenciandos que, em certa medida, serviram para fundamentar suas tomadas de decisão. Assim como exposto nas alíneas a seguir, esta análise contemplou a identificação de distintos componentes do modelo de argumentação de Toulmin, sua natureza e inter-relações CTS recorrentes. No bojo dos textos analisados, grande parte (8/11) se mostrou contrária à ênfase na geração hidrelétrica brasileira; assim como ilustramos na alínea (a), julgando necessário repensar a situação atual, mormente pelos impactos (negativos) sociais e ambientais. Apesar disso, um pequeno grupo (3/11) defendeu a continuidade dos investimentos centrados em hidrelétricas; conforme indicamos no exemplo da alínea (b), resguardando-se principalmente na viabilidade tecnológica e econômica de tais empreendimentos.

\section{a) Análise de uma argumentação contrária}

Neste caso, identificamos uma argumentação (vide figura 1) com recorrência a distintos componentes do modelo de Toulmin: dado D; garantias G1 e G2; apoio A; conclusão C1 com refutação R1; e, conclusão C2. Por meio dela, o licenciando reconheceu que a geração hidrelétrica brasileira deveria ser repensada, recomendando adotar uma nova matriz com fontes alternativas que fossem mais viáveis e não prejudicassem tanto o meio ambiente.

Figura 1: Esquema de uma argumentação contrária construído a partir de um dos textos produzidos pelos licenciandos. 


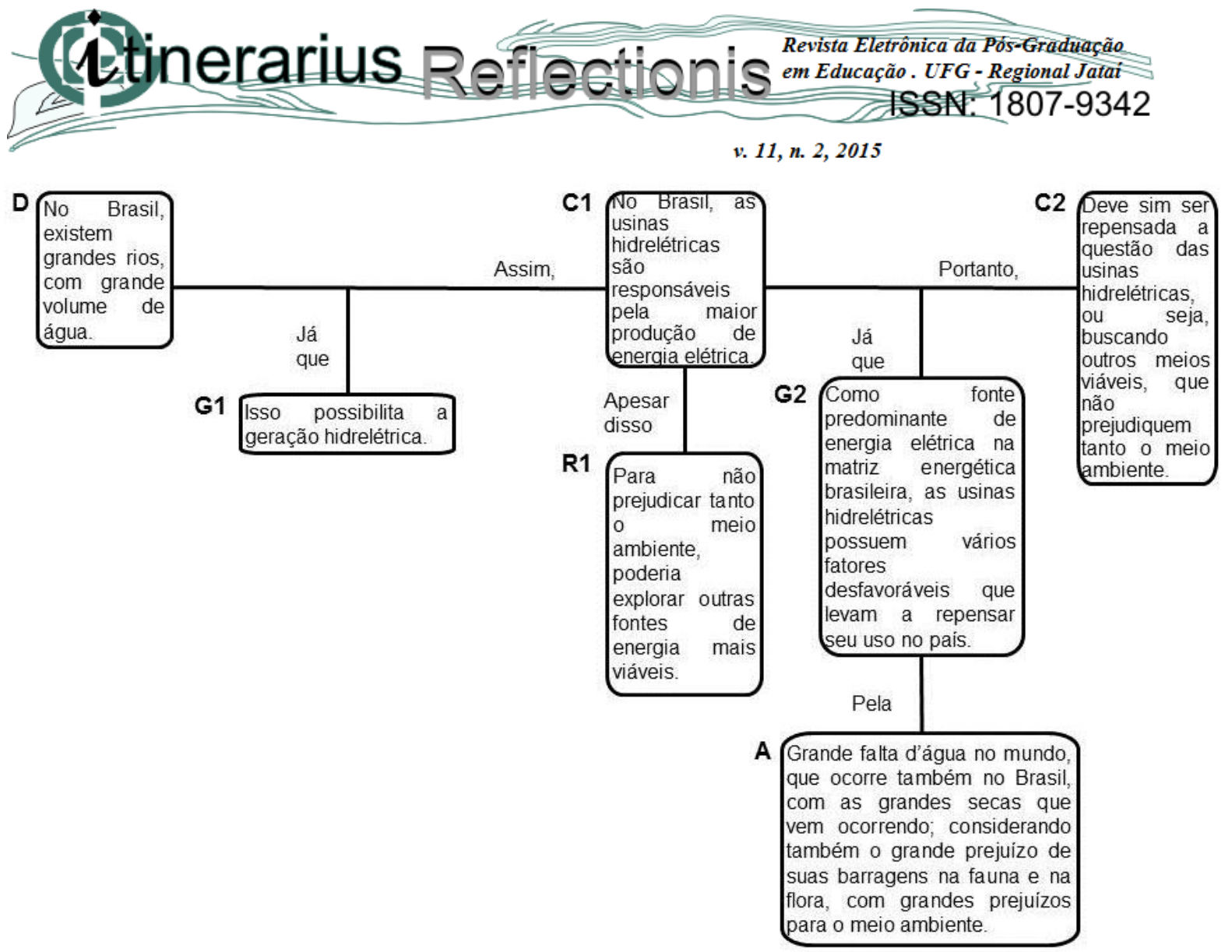

Fonte: Elaboração própria.

Constatamos que, nesta argumentação, há grande preocupação com os problemas de falta d'água e secas prolongadas que afetam diretamente a operação das hidrelétricas. Foram abordados conhecimentos de natureza científica, tecnológica e ambiental; com sinalizações de influências da $\mathrm{C}$ e/ou $\mathrm{T}$ na $\mathrm{S}$; e, influências da $\mathrm{S}$ na $\mathrm{C}$ e/ou $\mathrm{T}$. No entanto, embora o licenciando tenha reconhecido que a matriz vigente contém diversos pontos (principalmente, ambientais) que são "desfavoráveis", não chegou a adentrar-se em reflexões mais profundas sobre a questão de interesses materialistas e capitalistas (DAGNINO, 2010a).

\section{b) Análise de uma argumentação favorável}

De modo similar ao anterior, neste caso, também identificamos uma argumentação (vide figura 2) que continha uma estrutura justificatória com variados componentes do modelo de Toulmin: dado D; garantias G1 e G2; apoios A1 e A2; conclusão C1 com refutação R1; e, conclusão C2 com refutação R2. Porém, o licenciando julgou que a ênfase na geração hidrelétrica brasileira deveria continuar. Embora tenha reconhecido que esta opção tecnológica também gera impactos negativos ao meio ambiente, foi destacado que seu custo de produção era bem mais compensativo do que em uma termelétrica ou termonuclear. 
v. 11, n. 2, 2015

Figura 2: Esquema de uma argumentação favorável construído a partir de um dos textos produzidos pelos

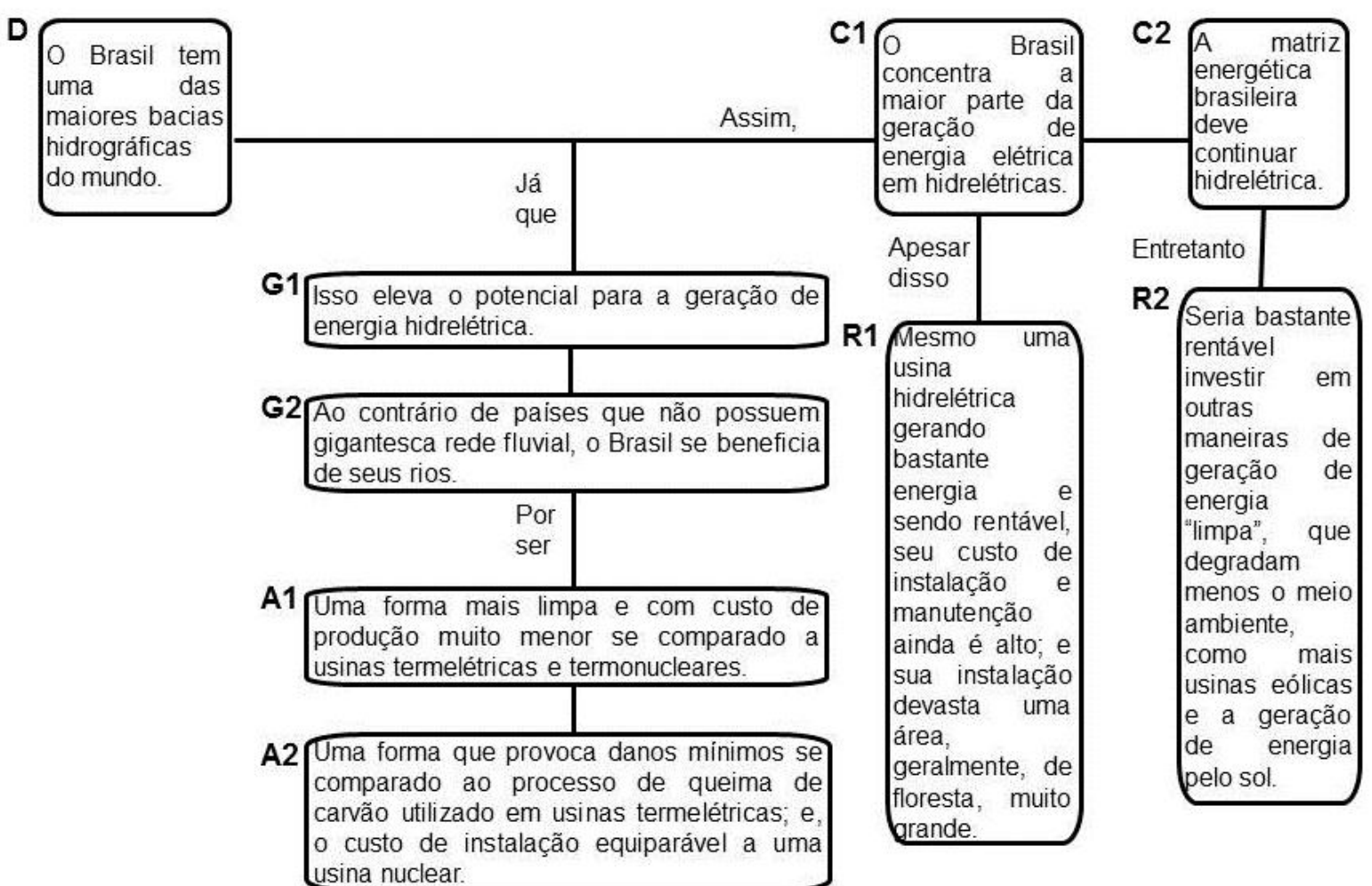

Fonte: Elaboração própria.

Verificamos que além de apresentar conhecimentos de natureza científica, tecnológica, econômica e ambiental, o licenciando fez referências a influências da C e/ou T na S; influências da S na C e/ou T; e, natureza da T - apontada como "mais limpa". Contudo, embora exista nesta argumentação certa preocupação com repercussões negativas relativas à degradação ambiental, há indícios de uma "racionalidade do sistema tecnológico que tem sido determinada pela lógica da maximização do lucro e a minimização dos custos" (SANTOS, 2008, p. 125), sendo que o fator "econômico" parece se sobrepor aos demais. Uma lógica que prioriza o capital sobre os valores humanos. Isto ficou bastante evidente no trecho em que o licenciando apontou que seria "bastante rentável" investir em outras maneiras de geração de energia, como usinas eólicas e a geração de energia pelo sol, realçando uma tecnologia que parece atender mais a interesses materialistas e capitalistas de uma minoria (DAGNINO, 2010b) do que às reais necessidades da sociedade.

\section{CONSIDERAÇÕES FINAIS E ASSUNÇÕES}


Neste estudo, constatamos tensões, consensos e possíveis deslocamentos acerca de concepções de inter-relações CTS na temática matriz energética, por parte dos sujeitos participantes. Além disso, o quadro de análise de argumentação proposto neste trabalho viabilizou uma compreensão ampliada da estrutura justificatória dos argumentos produzidos pelos licenciandos. De modo geral, tais argumentos continham dados, garantias, apoios, conclusões e refutações. Porém, não explicitavam qualificadores. Não obstante, embora exista certo fatalismo quanto às apostas futuras em uma matriz energética nacional pautada, principalmente, no petróleo e na geração hidrelétrica, identificamos sinalizações de aspirações, por parte dos sujeitos pesquisados, pela transição para outras fontes renováveis (como solar e eólica). Contudo, em nenhum momento foi mencionada alguma correlação dessa questão com a problemática do atual modelo de produção e consumo de bens materiais, alimentado por determinada matriz, que se ancora na obsolescência programada e no consumismo desenfreado.

Em nosso entendimento, é bastante pertinente repensar a matriz energética, no sentido de buscar fontes que sejam mais "limpas" e renováveis. Entretanto, só isso não basta, pois não haveria, dentro do modelo socioeconômico vigente, recursos suficientes para atender à crescente demanda de energia degradada. Diante disso, sugerimos a instauração de novas práticas pedagógicas para tratar dessas questões na formação inicial de professores, não apenas pela carência de conhecimentos sobre diferentes fontes e seus impactos (positivos e negativos), mas pela necessidade de se avançar em processos formativos que viabilizem desenvolver concepções mais críticas das inter-relações CTS, no sentido de reconhecer como tudo isso se articula à busca por um outro modelo de desenvolvimento que se serve de uma nova matriz e ponha em xeque a ideia de "progresso infinito" tão hegemônica no mundo.

\section{REFERÊNCIAS}

ABREU, T. B.; FERNANDES, J. P.; MARTINS, I. Levantamento sobre produção CTS no Brasil no período de 1980-2008 no campo de Ensino de Ciências. Alexandria, v. 6, n. 2, p. 332, jun. 2013.

AIKENHEAD, G. S.; RYAN, A. G.; FLEMING, R. W. Views on science-technology society. Canada: University of Saskatchewan Press, 1989. Disponível em <www.usask.ca/education/people/aikenhead/vosts.pdf>. Acesso em 20 out. 2014.

BERMANN, C. Energia no Brasil: Para quê? Para quem? Crise e alternativas para um país sustentável. - $2^{\text {a }}$ Edição - São Paulo: Livraria da Física, 2003. 


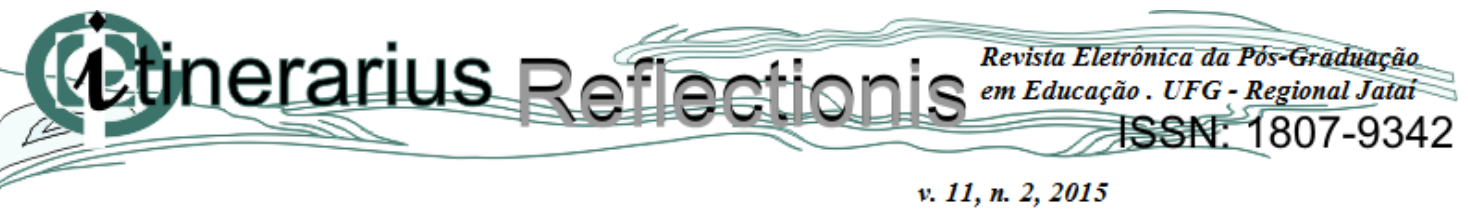

BRONZATTI, F. L.; IAROZINSKI, A. Matrizes energéticas no Brasil: cenário 2010-2030. In: XXVIII Encontro Nacional de Engenharia de Produção. Rio de Janeiro, 2008.

CHRISPINO, A.; LIMA, L. S. de; ALBUQUERQUE, M. B. de; FREITAS, A. C. C. de; SILVA, M. A. F. B. da. A área CTS no Brasil vista como rede social: onde aprendemos? Ciência \& Educação, v. 19, n. 2, p. 455-479, 2013.

DAGNINO, R. A tecnologia social e seus desafios. In: DAGNINO, Renato (Org.). Tecnologia social: formação para construir outra sociedade. - $2^{\mathrm{a}}$ Edição - Campinas: Komedi, 2010a.

Em direção a uma teoria crítica da tecnologia. In: DAGNINO, Renato (Org.). Tecnologia social: formação para construir outra sociedade. - $2^{\mathrm{a}}$ Edição - Campinas: Komedi, 2010b.

DUSEK, V. Filosofia da tecnologia. São Paulo: Edições Loyola, 2009.

FOUREZ, G. A construção das ciências: introdução à filosofia e à ética das ciências. São Paulo: UNESP, 1995.

Crise no ensino de Ciências? Investigações em Ensino de Ciências, v.8,n.2, ago. 2003.

JAPIASSU, H. Ciência e destino humano. Rio de Janeiro, Himago, 2005.

MOREIRA, M. A. Metodologias de pesquisa em ensino. São Paulo: Editora Livraria da Física, 2011.

PAIVA, R. U. P. de. Petróleo e a Física: uma visão contextualizada para o ensino médio. Dissertação (Mestrado em Ensino de Ciências e Matemática). Pontifícia Universidade Católica de Minas Gerais, Belo Horizonte, MG, 2012.

PATRONIS, T.; POTARI, D.; SPILIOTOPOULOU, V. Students' argumentation in decisionmaking on a socio-scientific issue: implications for teaching. International Journal of Science Education, v. 21, n. 7, p. 745-754, 1999.

PINTO, A. V. O conceito de tecnologia. Rio de Janeiro: Contraponto, 2005.

REIS, L. B.; FADIGAS, E. A. F. A.; CARVALHO, C. E. Energia, Recursos Naturais e a Prática do Desenvolvimento Sustentável. - 2 Edição - Barueri: Manole, 2012.

SANTOS, W. L. P. dos. Educação CTS e cidadania: confluências e diferenças. Amazônia Revista de Educação em Ciências e Matemáticas, v. 9, n.17, p. 49-62, jul. 2012.

SANTOS, W. L. P. dos ; SCHNETZLER, R. P. Educação em Química: Compromisso com a cidadania. - 4a Edição - Ijuí-RS: Editora Unijuí, 2010.

TOULMIN, S. E. Os usos do argumento. - $2^{\text {a }}$ Edição - São Paulo: Martins Fontes, 2006.

ZEN, E. L. Movimentos sociais e a questão de classe: um olhar sobre o movimento dos atingidos por barragens. Dissertação (Mestrado em Sociologia). Universidade de Brasília, Brasília, DF, 2007. 